\title{
USE OF SELF COMPACTING CONCRETE IN MASS HOUSING WITH CRUSHED SAND AS FINE AGGREGATE AND SNF BASED SUPER PLASTICIZERS
}

\author{
V.Umamaheshwaran ${ }^{1}$, L.S.Kannan ${ }^{2}$ \\ ${ }^{I}$ Asst.ManagerConcrete Management Department L\&T Construction B\&F IC, \\ umamaheswaran@Intecc.com \\ ${ }^{2}$ Head, Concrete Management Department L\&T Construction B\&F IC \\ lsk@lntecc.com
}

\begin{abstract}
The Indian construction industry is growing at a rapid pace to meet the housing and other infrastructure requirements. Our central government is also looking at housing for all by the 2020. However the question is are we doing the sustainable quality construction at all levels to meet the demand from various classes of people. And the other important parameter to be looked into is time required for constructing these structures. Here the modern construction methods comes in help to meet both the criteria of faster and durable construction. One such construction method for mass housing is the concept using shear wall technology. Here the entire structure is constructed with concrete with all the utilities in built in it.

The concrete to be used in such structures should be of self-compacting in nature because of the thin walls and heavy reinforcements. The thickness of walls vary from $75 \mathrm{~mm}$ to $200 \mathrm{~mm}$. This walls are constructed along with the slab so that the structure is monolithic.

The special requirement for concrete used in this type of structure is that the ultimate strength of concrete can be in the ranges of 25 to $30 \mathrm{~N} / \mathrm{mm} 2$ but needs about $15 \mathrm{~N} / \mathrm{mm} 2$ for removal of formwork. Thus the concrete should be robust in nature which can be made with the locally available materials and also economically viable.

A concrete for this should be self-compacting which meets the requirements of EFNARC 2005 and also practically suitable according to the site needs. The concrete is designed considering the above parameters and successfully implemented across various project sites in India.

The fresh concrete properties such as flow, flow retention, placing and hardened concrete properties such as compressive strength, Modulus of elasticity, good finish are studied across various project sites.
\end{abstract}

Keywords: Self Compacting Concrete, Crushed Sand, Admixtures, And Mass Housing

\section{IMPORTANCE OF STUDY}

The requirements of Self Compacting Concrete are not given in any of the Indian codes. Only EFNARC 2005 gives the recommendations on SCC. While the recommendations given on the SCC in general gives an outline on the features of SCC, it does not fully give any optimistic mix design procedure for Indian condition and specific structural and project needs. Thus a study has been attempted to check the SCC used in various project sites across India. The quality of materials plays a very important role in the performance of concrete especially in self-compacting concrete. The type of fine aggregate and admixture used in self-compacting concrete is of critical importance and hence this study focus on the use of crushed sand as find aggregate and SNF based superplasticizers.

\section{TYPES OF SCC}

There are two methods of producing SCC. Viscosity Modifying Agent type and Powder type. Based on the project / structural needs and availability of materials any of the two types can be used.

\subsection{VMA type SCC}

Here the Viscosity modifying agents (VMA) usually water soluble polymers are used in the concrete to make the concrete more cohesive. When using high amount of superplasticizers the concrete tends to bleed and to counter act that and increase the viscosity of the concrete VMA's are added into the concrete. The quantity of VMA will be very less in the range 0.1-0.2 \%. Sometimes the superplasticizers came with pre mixed VMA. In using VMA type admixture the powder content need not be too high as in case of Powder type SCC.

\subsection{Powder type of SCC}

Here the mix is modified by use of high powder volume in the range of 0.2 to 0.22 . The powder volume is calculated by volume of materials less than 125 microns. These generally consists of cementitious materials like OPC, Fly ash, GGBS, Microsilica, Metakaolin etc. the water content will be as similar to normal concrete but since the cementitious content and the powder content is high the water binder ratio will be low and to get the required workability super 
plasticizers are used. The water binder ratio should be in the range to ensure the cohesiveness and deformability. A free water binder ratio of $0.25-0.45$ is preferred depending upon the grade of concrete, workability and other properties required.

\section{DESIGN REQUIREMENTS}

Compared to conventional buildings where only beams and columns participate in the structural behavior, in RC Walled structure the entire building will participate in resisting forces. So, the structure will be strong, slim and sleek. As concreting will be done always in controlled environment, for RC walled structure quality will be at its best. It will nullify all the quality weak points involved in block work.Structural RC walls are invariably stiffer than framed structures, therefore for High rise structures, lateral deflections will be controlled significantly than framed structures, though it attracts little more additional lateral load.In RC walled structures, structural redundancy is very high, by which there will be not any catastrophic failures. $\mathrm{RC}$ walled structures are integrally connected to each other to form like a box from top to bottom, this will enable the system not to have isolated key elements which will endanger the structure.Load transfer and distribution is uniform so, failure is not sudden as compared with framed structure.RC walled structures will perform very well in cyclic loading like seismic loading, whereas framed structures will subject to heavy permanent rotations which will damage the block work and finishes.During the severe earthquakes also, $\mathrm{RC}$ walled structures will subject to micro cracking only, which can be restored by nominal grouting.

\section{CONCRETE PROPERTIES}

The concrete properties at both fresh stage as well as hardened stage is to be studied carefully to modify the mix to suit the project / structural needs. In the fresh stage properties such as flow and $v$ funnel values are tested. In the hardened stages the most important property looked into is compressive strength of the concrete, but the importance given in this type of project / structure is the early strength requirement to deshutter the formwork and defect free smooth finish to enhance the aesthetics of the building.

\subsection{Fresh Concrete Properties}

Considering the requirements of design a normal concrete with a slump of $80-130 \mathrm{~mm}$ with $20 \mathrm{~mm}$ maximum size of aggregate will be very difficult to place and compact in the slender wall structure. Also considering the pumping and placing requirements for tall towers the concrete needs to be with a very high flowing capacity. With a very high congestion of reinforcement the maximum size of aggregate cannot be the regular $20 \mathrm{~mm}$ or $25 \mathrm{~mm}$. Also considering the high cementitious content to get the free flowing characteristics required of SCC, the specific surface area needs to be more. Thus a maximum size of $12.5 \mathrm{~mm}$ or $10 \mathrm{~mm}$ will be both optimal and convenient. In some cases a small quantity of $20 \mathrm{~mm}$ to an extent of about $30 \%$ of coarse aggregate is used to achieve the balance between using optimizing the specific surface area required and the reducing the water demand thereby reducing the cement content to coat the aggregate.

The other requirement is to find out the exact flow requirements for the specific structure. Here depending upon the requirements of thickness of the member (walls), Dimensions of the structure (length and widthof the rooms), Height of pour, and congestion of reinforcement. The congestion of reinforcement along with other services lines such as electrical, plumbing fittings and electrical boxes (Figure -1) will need to be considered in fixing the workability requirements. Higher flow of concrete can be unnecessary and create problems like delay in initial setting time, reduced strength more cost. A lower flow of concrete will give difficulties in pumping, placing and ensuring the full compaction. Also since most of the concrete structures will not be plastered and the concrete surface needs to be smooth and defect free.

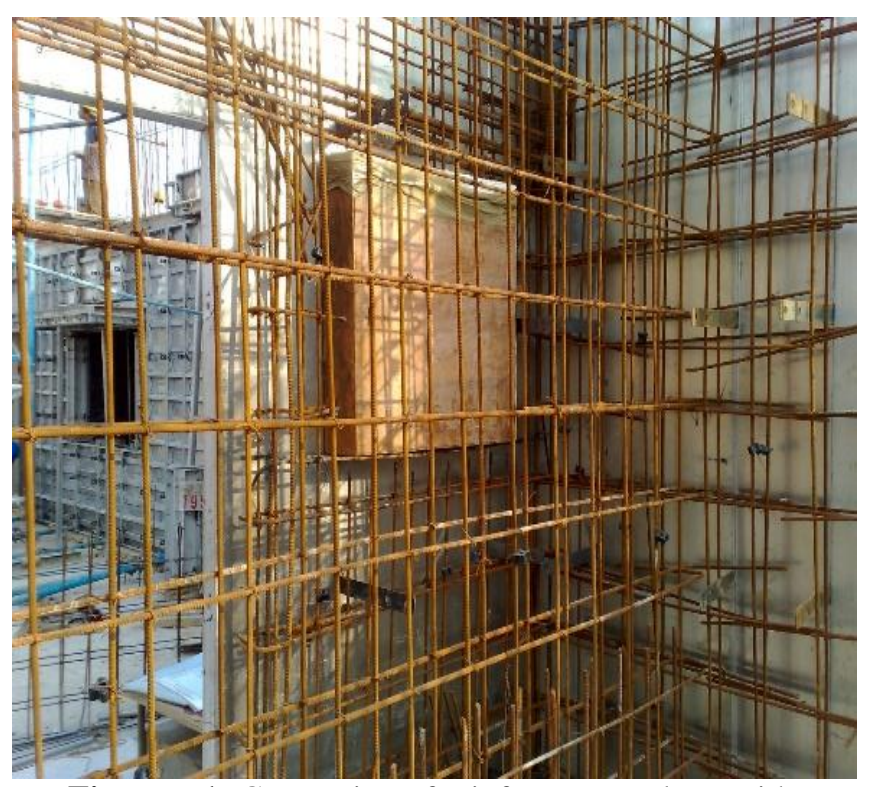

Figure - 1: Congestion of reinforcement along with electrical distribution box

\subsection{Hardened concrete}

The hardened concrete needs to be strong and durable. But one consideration here is the early strength requirements for the early de-shuttering. Even though the final strength requirement for most of the structure is in the range of 30 to $40 \mathrm{~N} / \mathrm{mm}^{2}$, because of the early strength required the overall final strength will be higher than the actual strength required. An early strength of $15 \mathrm{~N} / \mathrm{mm}^{2}$ is required before deshuttering the formwork. The early strength requirement and the subsequent deshuttering is decided with cycle time requirements of the project. In general the requirement is 15 $\mathrm{N} / \mathrm{mm}^{2}$ at 24-36 hours before starting the deshuttering.

\section{MIX PROPORTION}

The mix proportion for SCC is slightly different from the conventional concrete. The fine aggregate content will be much more than the normal concrete and the coarse aggregate content will be less than the normal concrete. Since this being powder type self-compacting concrete, the 
cementitious content will be slightly higher than the normal concrete. Also the mix is used in the housing projects where aluminum formwork is used, the compressive strength required for early deshuterring needs to be met. Based on the compressive strength of concrete the formwork is demoulded at 24 or 36 hours from the time of casting. In line with the above strength requirement concrete mix is designed with the later strength slightly higher than the grade of concrete. In general most of this type of affordable mass housing structures are designed with the concrete grades ranging from M20 to M35.

\subsection{Coarse aggregate}

To reduce the frequency of collision and contact between aggregate particles it is necessary to reduce the coarse aggregate content and also the maximum size of the coarse aggregate will be less than the normal concrete. Usually $12.5 \mathrm{~mm}$ or $10 \mathrm{~mm}$ aggregate is used to match the high specific surface area required for the high paste content of SCC.

\subsection{Fine aggregate}

The choice of fine aggregate is very important in case of powder type as it needs to supply some quantity of powder content (less than 125 micron) but should not be too fine in such will increase the water demand and may pull down the strength. As such the crushed sand meeting the grading requirements of IS 383 will be good enough to make SCC. Crushed sand with a fineness modulus in the range of 2.5 to 3.1 was found to be effective in designing powder type SCC based on the various project mixes across the country.A sample sieve analysis result of Crushed sand used in SCC is shown it Table 1

Table - 1: Sieve analysis of crushed sand

\begin{tabular}{|l|l|}
\hline $\begin{array}{l}\text { Col 1 } \\
\text { IS Sieve }\end{array}$ & $\begin{array}{l}\text { Col } 2 \\
\text { Percentage passing }(\%)\end{array}$ \\
\hline $10 \mathrm{~mm}$ & 100 \\
\hline $4.75 \mathrm{~mm}$ & 96.9 \\
\hline $2.36 \mathrm{~mm}$ & 83.3 \\
\hline $1.18 \mathrm{~mm}$ & 60.5 \\
\hline 600 micron & 47.2 \\
\hline 300 micron & 28.6 \\
\hline 150 micron & 15.3 \\
\hline 75 micron & 4.0 \\
\hline
\end{tabular}

\subsection{Admixture}

Sulphonated Naphthalene Formaldehyde (SNF) based super plasticizers were used for the production of SCC. It is mandatory that the admixture be compatible with the cement used. From the different compatibility tests and various trials the compatibility of cement and admixtures is ensured.The use of Viscosity Modifying Agent (VMA) was not necessary as the mix had enough cohesiveness and viscosity to suit the project / Structural needs. The properties of the SNF based admixtures are shown in Table 2

Table - 2: Properties of admixture

\begin{tabular}{|l|l|}
\hline $\begin{array}{l}\text { Col } 1 \\
\text { Properties }\end{array}$ & $\begin{array}{l}\text { Col } 2 \\
\text { Values }\end{array}$ \\
\hline Colour & Brown liquid \\
\hline Specific Gravity & $1.22 \pm 0.02$ \\
\hline Chloride content & Nil \\
\hline Solid content & $42 \%-45 \%$ \\
\hline
\end{tabular}

\section{SLUMP FLOW TEST}

The most common test to measure the workability is Slump test for normal concrete. For SCC the same test is modified slightly and performed as slump flow test. Tamping is not necessary in the flow test. As the housing unit in full has to be casted in a single monolithic construction the requirements of slump/flow should be applicable for both vertical and horizontal structures (walls and slabs). The flow test results are shown in the Table 3.

Table - 3:Flow of SCC at various time intervals

\begin{tabular}{|l|l|}
\hline $\begin{array}{l}\text { Col } 1 \\
\text { Time }\end{array}$ & $\begin{array}{l}\text { Col } 2 \\
\text { Flow values }(\mathrm{mm})\end{array}$ \\
\hline $0 \mathrm{~min}$ & 700 \\
\hline $30 \mathrm{~min}$ & 660 \\
\hline $60 \mathrm{~min}$ & 610 \\
\hline $90 \mathrm{~min}$ & 550 \\
\hline $120 \mathrm{~min}$ & 510 \\
\hline
\end{tabular}

The flow is tested at various time periods and the required flow at the time of placing considering the time for transportation. The following Figure 2 shows the flow test carried at one of the project site.

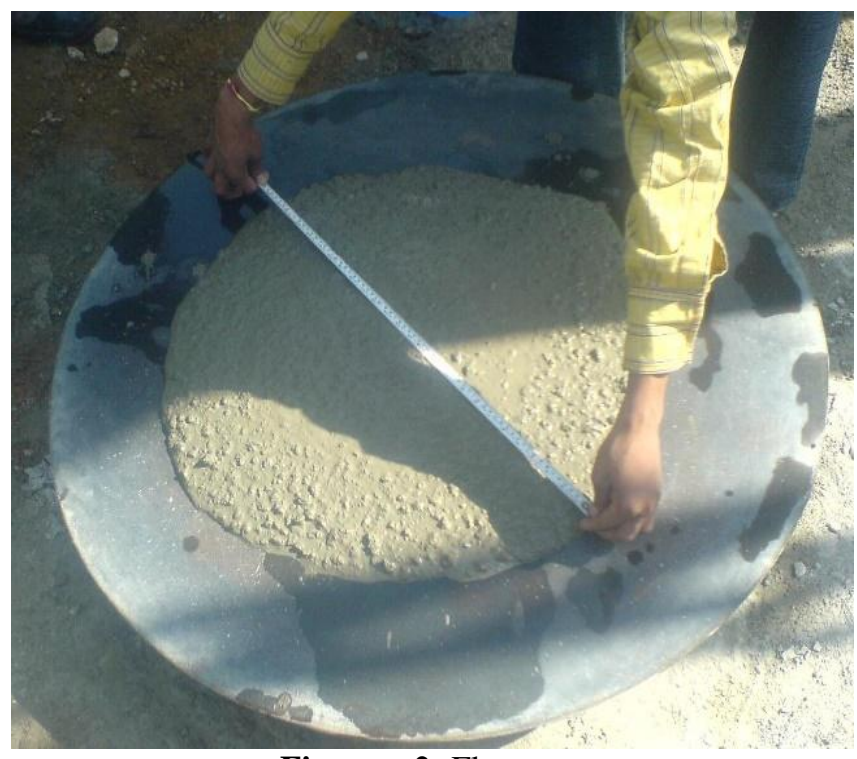

Figure - 2: Flow test 


\section{V FUNNEL TEST}

The ability of concrete to flow through smaller openings is evaluated by $\mathrm{V}$ funnel test. In this test the $\mathrm{V}$ funnel time is measured for the SCC to pass through the lower opening. If the time is quicker then it means the flowability is more and if the time is slower then it means the flowability is less. The V Funnel test values are shown in Table 4

Table - 4:V Funnel time

\begin{tabular}{|l|l|}
\hline $\begin{array}{l}\text { Col } 1 \\
\text { Time }\end{array}$ & $\begin{array}{l}\text { Col } 2 \\
\text { V Funnel time (Seconds) }\end{array}$ \\
\hline 0 min & 8 \\
\hline 5 min & 11 \\
\hline
\end{tabular}

\section{PUMPING}

Normal concrete pumps can be used to pump the Self compacting concrete. The pumping distance both vertical and horizontal will be criteria for choosing the capacity of pumps. It was observed that the powder type SCC reduces the operating pressure of the pump. The SCC mix was pumped up to a vertical height of $200 \mathrm{~m}$ in one of the project sites. The placing of concrete needs to be taken care in accordance with the pump and pumping pressure. Figure 3 shows the placing of SCC in a wall cum slab monolithic construction.

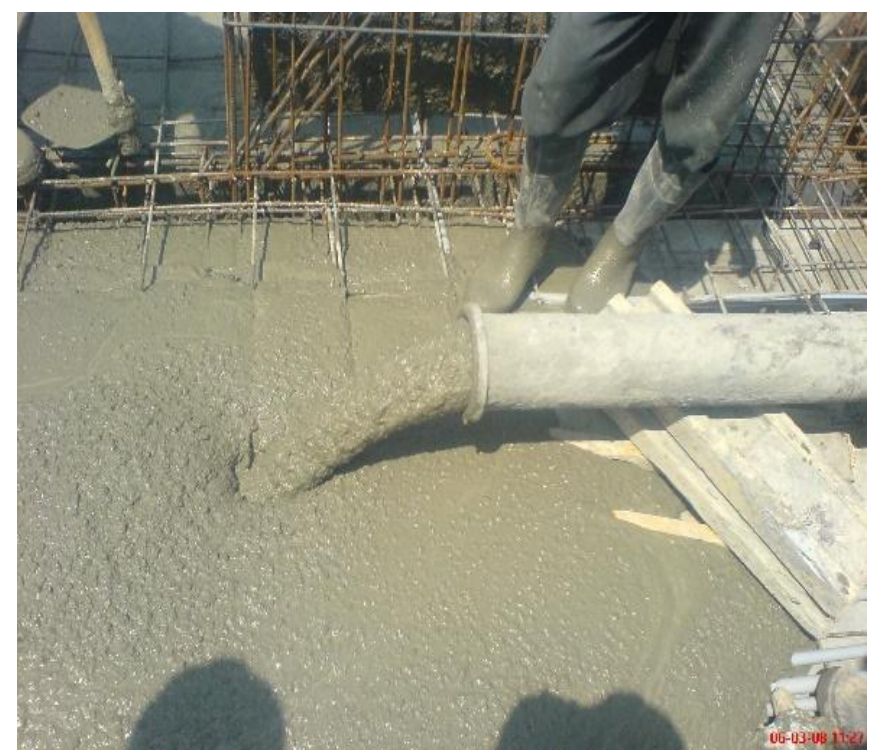

Figure - 3: Pumping of SCC

\section{CONCLUSIONS}

The demand for affordable housing is ever increasing and to meet this a lot of innovative construction practices has evolved. The use of Self Compacting Concrete for the mass housing to make the construction faster and simpler is very much the need of the day. However choosing the right materials for the SCC based on project/structural needs is a significant activity in providing the optimal, economical and sustainable use of resources. Based on the successful completion of many of such housing projects, there are different ways we can make SCC for the project needs. The usual practice of VMA based SCC is not necessary for all the project/structural needs. Powder type SCC with crushed sand as fine aggregate and SNF based superplasticizers have been found to meet the requirements. A well graded fine aggregate (crushed sand) meeting the requirements of IS 383, and a good SNF based superplasticizer which is compatible with the cement used is sufficient enough to produce the SCC which meets the requirements for the project/Structural needs. Therefore the materials should be selected based on the project requirements and the given local conditions. Figure 4 shows the structure done with powder type SCC using crushed sand as fine aggregate and SNF based superplasticizers.

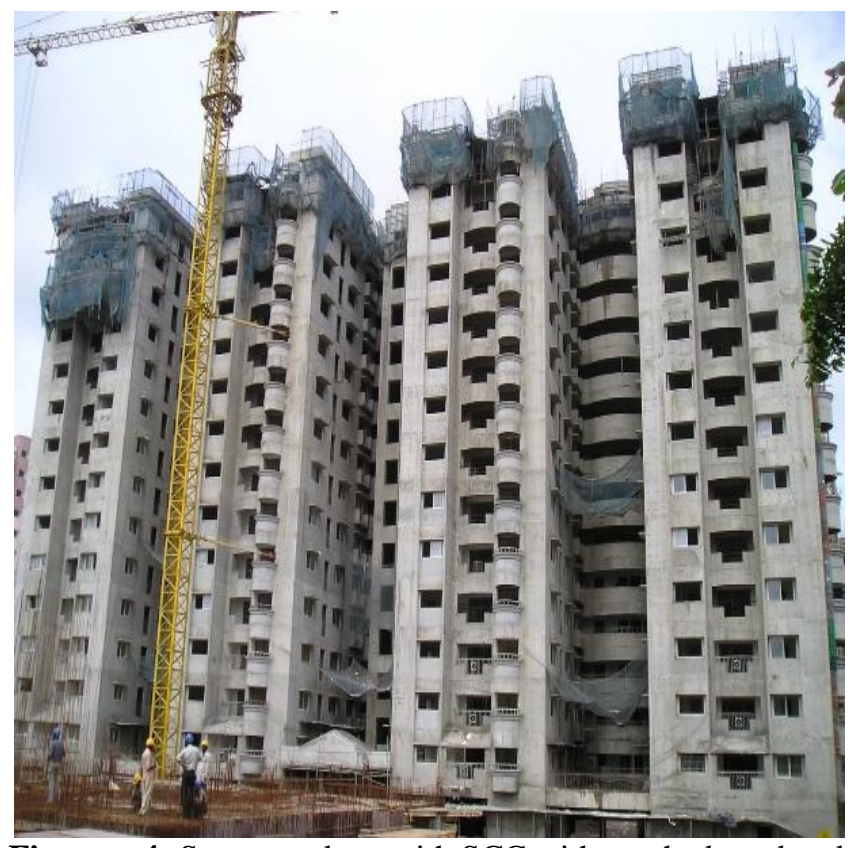

Figure - 4: Structure done with SCC with crushed sand and SNF admixture

\section{REFERENCES:}

[1]. IS: 383 (1970), Specification for Coarse and Fine aggregates from Natural Sources of Concrete, Bureau of Indian Standards, New Delhi.

[2]. IS: 456 (2000), Code of practice for Plain and Reinforced Concrete (Fourth Revision), Bureau of Indian Standards, New Delhi.

[3]. IS: 516 (1959), Methods of Tests for Strength of Concrete, Bureau of Indian Standards, New Delhi.

[4]. IS: 1199 (1959), Methods of sampling and analysis of concrete, Bureau of Indian Standards, New Delhi.

[5]. IS: 2386 (1963), Methods of Tests for Aggregates for concrete, Bureau of Indian Standards, New Delhi.

[6]. IS: 4031 (1966), Methods of Physical Tests for Hydraulic cement, Part 01-15, Bureau of Indian Standards, New Delhi.

[7]. EFFnarc May 2005 European Guidelines for SelfCompacting Concrete, Specification, Production and use. 


\section{BIOGRAPHIES}

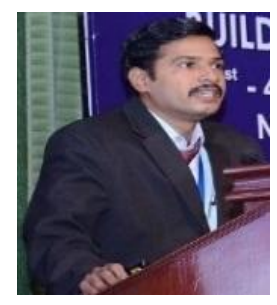

Mr.V.Umamaheshwaran working as Assistant Manager in Concrete Management Department of L\&T Construction Buildings and Factories Independent Company. He holds a master degree in Construction Engineering and Management. He is been actively working in the field of Concrete Technology for the last 14 years. His areas of interests include High strength / High performance concrete, Self-compacting Concrete, use of alternate materials, optimization of concrete mix design and training.

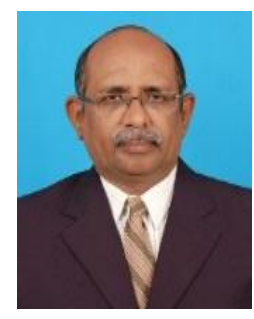

Mr.L.S.Kannan working as the Head of Concrete Management Department of L\&T Construction Buildings and Factories Independent Company. His contribution in the field of Concrete Technology dates back to more than 32 years. His work experience includes many important structures ranging from railways, power plants, cement plants, paper mills, bridges, dams and many high rise structures. He passionately train young engineers in the field of concrete practices and his expertise helps in trouble shooting of various issues at various projects across the nation and abroad. 